\title{
Pitting Corrosion of the Resistance Welding Joints of Stainless Steel Ventilation Grille Operated in Swimming Pool Environment
}

\author{
Mirosław Szala $(\mathbb{D}$ and Daniel Lukasik \\ Department of Materials Engineering, Faculty of Mechanical Engineering, Lublin University of Technology, Nadbystrzycka 36D, \\ 20-618 Lublin, Poland \\ Correspondence should be addressed to Mirosław Szala; m.szala@pollub.pl
}

Received 28 January 2018; Accepted 2 April 2018; Published 9 May 2018

Academic Editor: Kai Wang

Copyright (C) 2018 Mirosław Szala and Daniel Łukasik. This is an open access article distributed under the Creative Commons Attribution License, which permits unrestricted use, distribution, and reproduction in any medium, provided the original work is properly cited.

\begin{abstract}
This work focuses on the pitting corrosion of ventilation grilles operated in swimming pool environments. The ventilation grille was made by resistance welding of stainless steel rods. Based on the macroscopic and microscopic examinations, the mechanism of the pitting corrosion was confirmed. Chemical composition microanalysis of sediments as well as base metal using scanning electron microscopy and energy-dispersive spectroscopy (SEM-EDS) method was carried out. The weldments did not meet the operating conditions of the swimming pool environment. The wear due to the pitting corrosion was identified in heat affected zones of stainless steel weldment and was more severe than the corrosion of base metal. The low quality finish of the joints and influence of the welding process on the weld metal microstructure lead to accelerated deposition of corrosion effecting elements such as chlorine.
\end{abstract}

\section{Introduction}

The aesthetic appearance and the ease of keeping the surface clean, good strength properties, ductility, weldability, and corrosion resistance make the use of stainless steels encouraging for elements of the construction and equipment of swimming pools like ventilation grilles. Although polymer materials such as ABS (acrylonitrile butadiene styrene) and PVC (polyvinyl chloride) are relatively cheaper than stainless steel and can also be operated in pool conditions, none of them matches all the mentioned beneficial properties of stainless steel. Stainless steel elements are used to make swimming pool equipment, such as stairs, ladders, ventilation systems (e.g., ventilation grilles), barriers, drainage grills, or other decorative elements. These components can be made from stainless steel grades such as 1.4301, 1.4404, 1.4539, and 1.4547 [1-4], and their chemical composition is presented in Table 1.

According to the environmental corrosivity categories described by the standard [5], the interior of the swimming pool is classified as $\mathrm{C} 4$, on a 5-degree scale of corrosiveness
(C1: very low, C5: a very large corrosivity category). That is why one of the basic criteria for the metal materials selection used to build structures and elements of the swimming pool is their resistance to corrosion phenomena. Hence, the operating conditions of metal elements in the pool environment are unstable and difficult to describe, which can prevent grades dedicated to specific applications from meeting the requirements. The high price of more corrosion resistant stainless steel grades containing more expensive alloy components often prompts designers to choose cheaper, more available materials with inferior corrosion resistance. For example, it is a common mistake to use cheaper steel grade like 1.4301 instead of, for example, 1.4401 or 1.4404. The first of these materials is widely used in the construction of food processing equipment and industrial installations, but it corrodes easily in the swimming pool environment [6]. Grade 1.4404 , due to the presence of molybdenum and nitrogen, is described in the literature, as dedicated to the production of equipment and design of swimming pools [1-4]. However, in specific swimming pool applications, elements manufactured 
TABLE 1: Chemical composition of selected stainless steels according to EN 10088-1 standard [8].

\begin{tabular}{|c|c|c|c|c|c|c|c|}
\hline \multicolumn{2}{|l|}{ Steel grade } & \multicolumn{6}{|c|}{ Nominal chemical composition [\% by mass] } \\
\hline Name & Number & $\mathrm{C}$ & $\mathrm{N}$ & $\mathrm{Cr}$ & Mo & $\mathrm{Ni}$ & Other \\
\hline X8CrNil8-8 & $1.4301^{(\mathrm{a})}$ & $\leq 0,070$ & $\leq 0,11$ & $17,5 \sim 19,5$ & - & $8,0 \sim 10,5$ & - \\
\hline $\mathrm{X} 2 \mathrm{CrNi18}-9$ & $1.4307^{(\mathrm{a})}$ & $\leq 0,030$ & $\leq 0,11$ & $17,5 \sim 19,5$ & - & $8,0 \sim 10,5$ & - \\
\hline X5CrNiMol7-12-2 & $1.4401^{(a)}$ & $\leq 0,070$ & $\leq 0,11$ & $16,5 \sim 18,5$ & $2,0 \sim 2,5$ & $10,0 \sim 13,0$ & - \\
\hline X2CrNiMol7-12-2 & $1.4404^{(\mathrm{a})}$ & $\leq 0,030$ & $\leq 0,11$ & $16,5 \sim 18,5$ & $2,0 \sim 2,5$ & $10,0 \sim 13,0$ & - \\
\hline $\mathrm{X} 1 \mathrm{CrNiMoCu} 25-20-5$ & $1.4539^{(b)}$ & $\leq 0,020$ & $\leq 0,15$ & $19,0 \sim 21,0$ & $4,0 \sim 5,0$ & $24.0 \sim 26.0$ & $\mathrm{Cu}=1,2 \sim 2,0$ \\
\hline X1CrNiMoCuN20-18-7 & $1.4547^{(\mathrm{c})}$ & $\leq 0,020$ & $0,18 \sim 0,25$ & $19,5 \sim 20,5$ & $6,0 \sim 7,0$ & $17,5 \sim 18,5$ & $\mathrm{Cu}=0,5 \sim 1,0$ \\
\hline
\end{tabular}

from stainless steel grade 1.4404 undergo pitting corrosion, as described in [7].

Works $[1-4,6,7,9]$ describe examples of negative consequences of corrosion phenomena, observed for stainless steels used for swimming pool equipment. The effects of the general or pitting corrosion are usually losses related to the necessity of exchanging corroded elements, such as the case of corrosion of the ventilation duct [6] and drain [7] operated in the pool. In the case of load-bearing elements, pitting corrosion can cause the development of stress corrosion $[9,10]$. Pitting is an extremely localized attack that is manifested by holes, or pits, in the metal surface as well as especially in heat affected zones of weld joints [11-13]. Pitting is a particularly insidious form of corrosion since it is difficult to detect until the structure has been severely attacked $[4,6,7,12,14]$.

In preventing the occurrence of corrosion phenomena of steel elements used in swimming pools, the technological nature of their construction and assembly (e.g., welding) plays an important role. Designing elements should be carried out based on principles such as maintaining high surface smoothness, making structures without sharp corners and undercuts, designing self-cleaning structures, protecting gaps against accumulation of water and sediments in them, using appropriate joining techniques with high care, and the quality of the welding joints finish, so that the joints would have corrosion resistance similar to the base material $[1,12]$.

Stainless steel corrosion in elements operated in swimming pool environment is considered as a real problem. The literature survey indicates that there is little information about pitting corrosion of stainless steel resistance welding joints. Authors focus mainly on investigating the corrosion of fusion welding processes (e.g., [11, 15-17], [18, p. 304]), none of them influenced by pool environment. The conducted literature review indicates only one paper related to pitting corrosion of resistance welding weldment used in pools [6]. Hence, it can be acclaimed that the state of the art in the field of pitting corrosion resistance of stainless steel weldments operated at swimming pool environments is not entirely investigated.

The aim of the article is to investigate the corrosion of a ventilation grille operated in a swimming pool environment. The grille was made by resistance welding of stainless steel shaped rods.

\section{Material and Methodology of Research}

The ventilation grille was made of welded stainless steel rods. The tested element was part of the swimming pool ventilation system. The grille was mounted indoors and located at the inlet of the ventilation duct on the wall and had no direct contact with the pool water. The swimming pool atmosphere was characterized by significant humidity resulting from evaporation of pool water. The grille was operated for just a few months until it detected visible corrosion changes and its disassembly.

The temperature of the ventilation system elements was lower than the air temperature in the swimming pool. Chlorinated pool water had a $\mathrm{pH}$ close to 7.0. This led to the condensation of water vapor on the ventilation grille, creating conditions for corrosion phenomena to occur on its surface.

Figure 1 shows the examined element and was taken after dismantling the element, dictated by the change of the colour of the grille surface to "rusty." The presence of corrosion deposit products and pits was observed mainly in areas of joint heat affected zones (HAZ).

In order to recognize the corrosion mechanism, macroscopic and microscopic observations of the worn areas of ventilation grille focused on heat affected zones of resistance welded grille were made. Macroscopic examinations based on the observation of the surface and joint areas were made using a Nikon SMZ 1500 stereomicroscope. To reveal the topography of pitting surfaces, the samples were cleaned using ultrasonic washer in order to remove corrosion products and the steel grille was cross-sectioned on a metallographic cutter (Brillant 200) and then investigated using a Nikon MA200 metallographic microscope. Phenom World ProX scanning electron microscope with chemical composition of the steel and corrosive sediments analysis using SEM-BSD (backscatter electron detector) and SEM-topo modes were carried out.

\section{Results}

The object of our investigation was the ventilation grille presented in Figure 1. The weldment areas were mostly severely affected by corrosion, which is visible in optical photographs given in Figure 2 as well as in metallographic weldment cross section in Figure 3. Additionally, in photographs acquired 

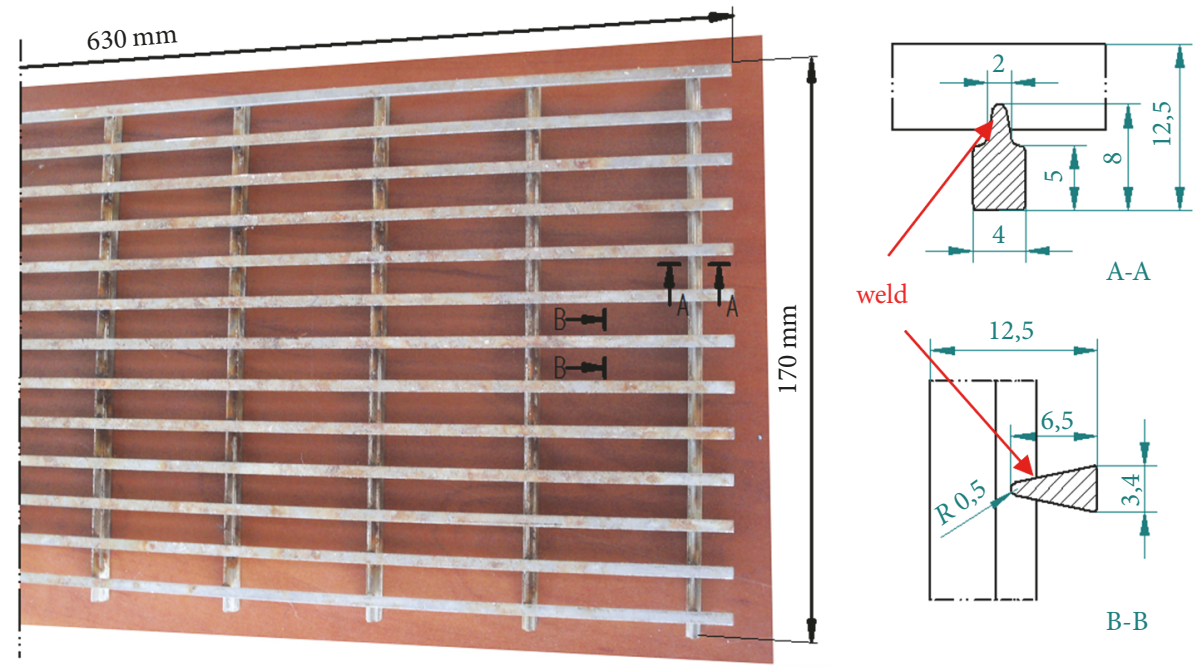

FIGURE 1: Ventilation grille made by resistance welding of stainless steel rods, dimensions in $\mathrm{mm}$.

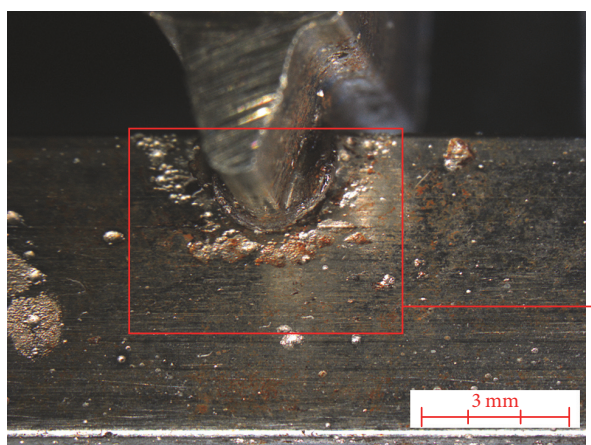

(a)

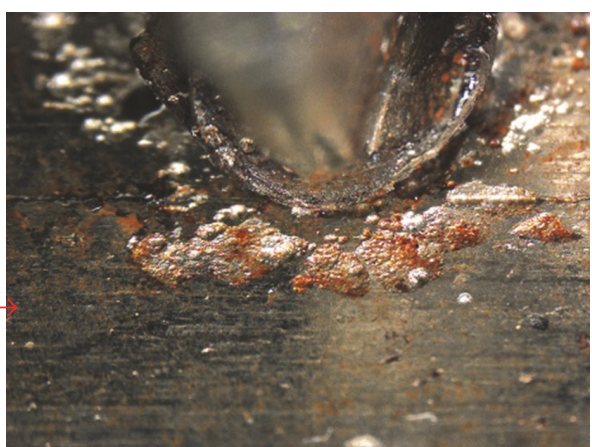

(b)

FIGURE 2: Resistance welding weldment corrosion (a) and magnified HAZ (b), stereoscopic microscope.

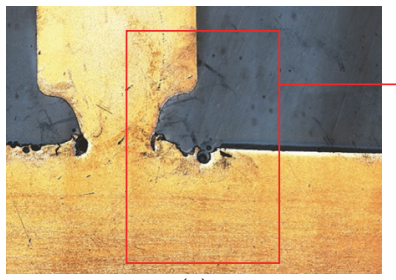

(a)

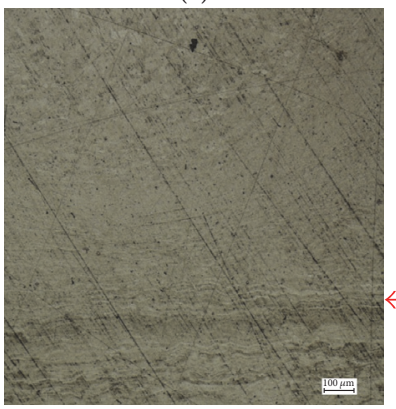

(b)

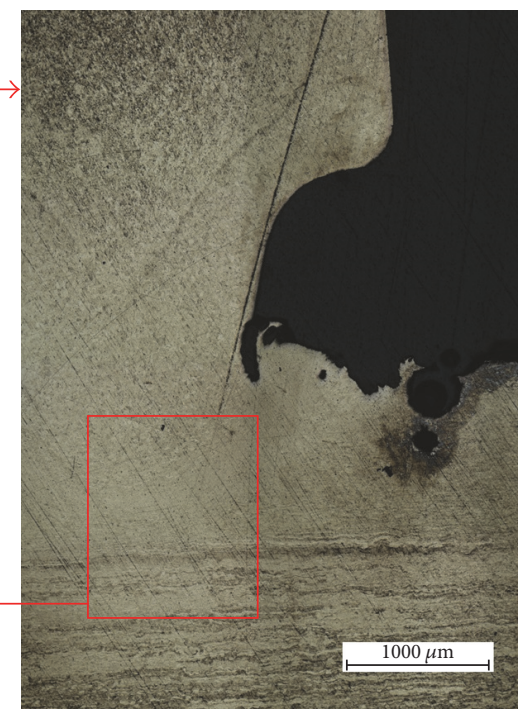

(c)

FIGURE 3: Corrosion pits observed in the cross section of joint (a) in the HAZ; (b, c) magnified selected area of microstructure of base metals and heat affected zone presented, metallographic microscope. 


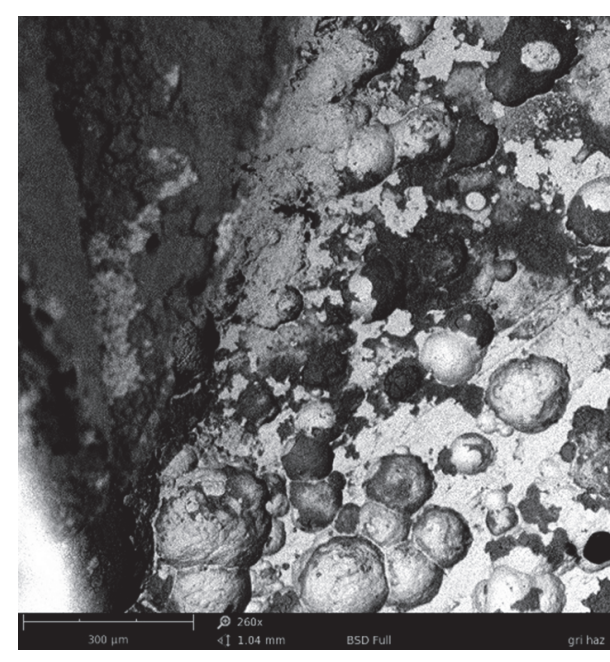

(a)

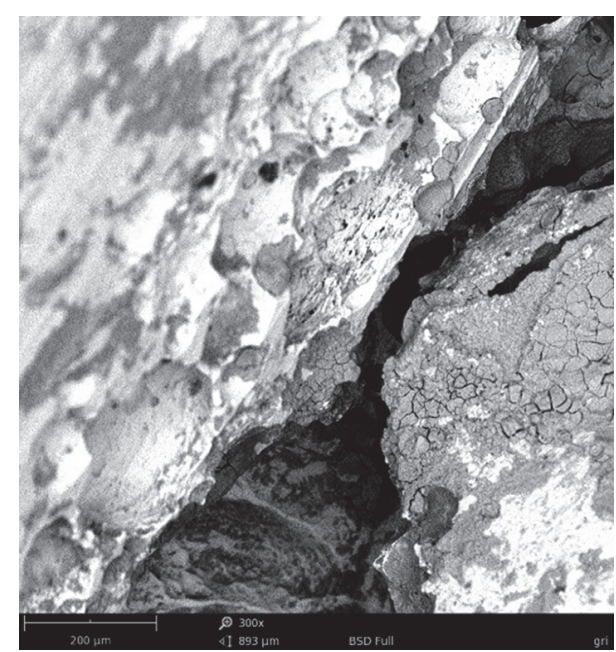

(b)

Figure 4: The effect of pitting observed in the HAZ (a) and crack between grille rods (b), SEM-BSD.

by the scanning electron microscope, corrosion pits and corrosive sediments are identified, Figure 4. Furthermore, Figure 5, Figure 6, and Table 2 contain the results of chemical composition of base metal and corrosive sediments.

\section{Discussion}

Stainless steels achieve corrosion resistance thanks to the passive layer of oxides spontaneously formed on the surface of the products. The passive film can be damaged and its restoration depends on the specific characteristics of the material and the environment. In the absence of a passive layer or its damage, the process of corrosion damage is intensified. The investigated grille was manufactured by electric resistance welding, as shown in Figures 1 and 2.

In addition, microstructure of weldment, which differs from the base metal, mostly affects corrosion resistance of stainless steel as presented in Figure 3(a). Results of metallographic investigations of the weldment acknowledged the anisotropy of the structure of welded rods, which derives from metal forming processes, so the area of the weldment that is plastically deformed and influenced by resistance welding process hence contains different microstructure from base metal (Figures 3(b) and 3(c)). In [11, 12], phenomena associated with welded joints, such as dendritic segregation, precipitation of secondary phases, formation of unmixed zones, recrystallization, and grain growth, are listed as influencing the corrosion resistance of the heat affected zone (HAZ). The operating conditions of the ventilation system resulted in deposition of chlorine condensate on the ventilation grille. The cyclic nature of the process led to an increase in the concentration of chlorine in selected places on the surface of the grille. This intensified the occurrence of local corrosion phenomena, including pitting corrosion. It is common knowledge that, at a higher temperature, the oxide film ceases to form due to the lower solubility of oxygen in the solution and the penetration potential decreases with increasing temperature. Garcia et al. [11] gave information that fusion welding processes can cause local changes in the composition of the welded material, which can alter the stability of the passive layer and its corrosion behaviour [15]. In addition, from the microstructural point of view, the formation of $\delta$-ferrite in stainless steel is another parameter taken into account, since it can be prejudicial because of its susceptibility to attack in a corrosion medium $[11,16]$, such as a swimming pool, a chlorine-rich environment. According to the literature, the pitting corrosion resistance in pool environment of stainless steel element can be increased using steels with a molybdenum content above $2.5 \%$ and chromium above $17 \%$ by weight, containing nitrogen.

Leda claims [19] that near nonmetal inclusions, grain boundaries, dislocations, surface nonuniformities, and the probability of corrosion attack increase. The metallurgical purity and homogeneity of steel elements have a great influence on corrosion resistance [13]. Also, the lack of nonmetallic inclusions, especially those located on the surface, in stainless steel such as sulphur are factors that improve corrosion resistance [20]. On the contrary, in the investigated grille, areas of poor weldment finish and surface nonuniformities were identified, visible in Figure 2. They were produced during the resistance welding process due to heat imputed, force used in resistance welding process, and atmosphere. These areas must have been finishing, machined, and chemically etched after welding. Poor metal finish of weldment accelerates concentration of corrosive deposits (e.g., chlorinerich) that can influence corrosion of weldment. In order to prevent the corrosion of the ventilation grille to remove chlorine-containing deposits from its surface, it is possible to periodically wash its surface. We also proposed that grilles produced by resistance welding process could not met requirements of harsh operating pool environment due to difficulties connecting to finishing treatment of weldment.

The formation of corrosion pits on stainless steel elements in the atmosphere of the swimming pool is caused mostly 


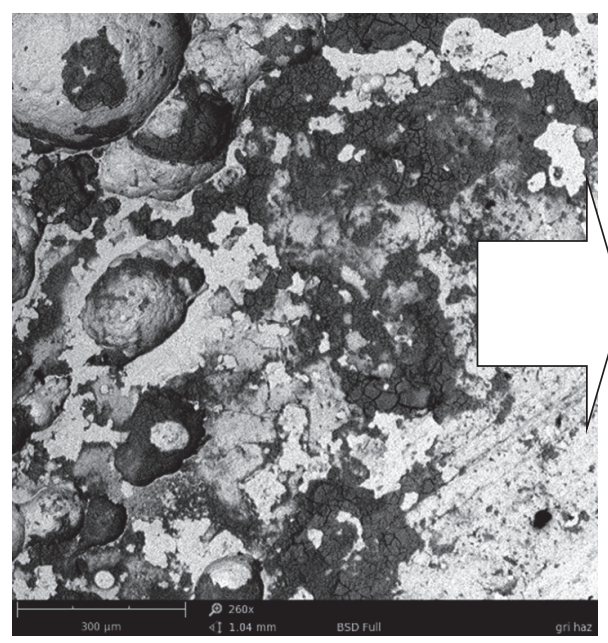

(a)

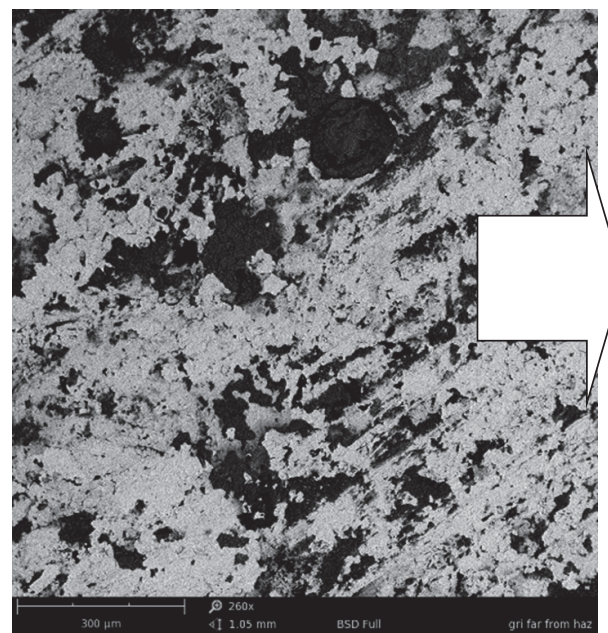

(c)

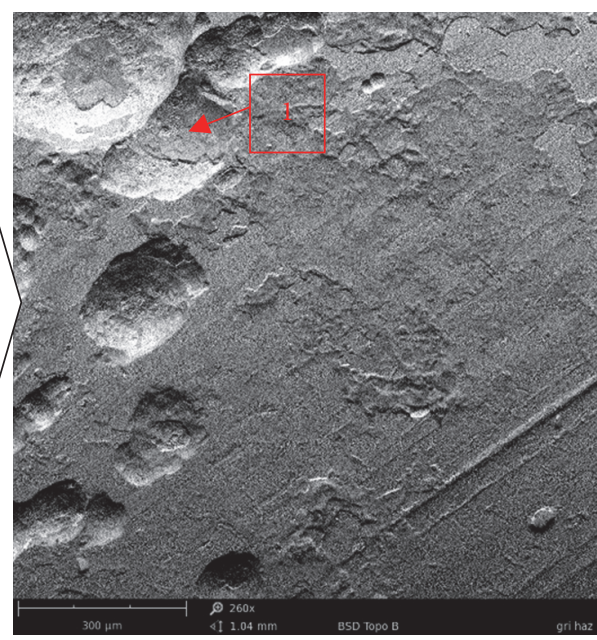

(b)

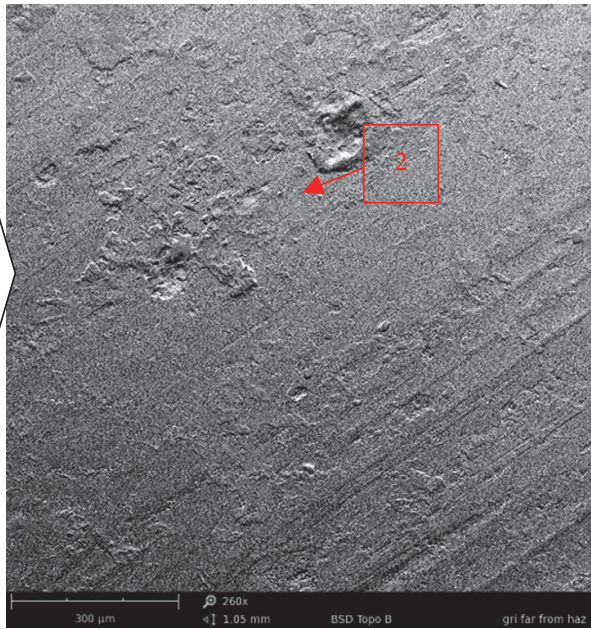

(d)

FIGURE 5: Comparison of grille surfaces observed in the heat affected zone HAZ (a, b) and in distance of HAZ (c, d). SEM-BSD and SEMBSD-topo modes. Points 1 and 2 are locations of chemical analysis; results presented in Figure 6 and Table 2.

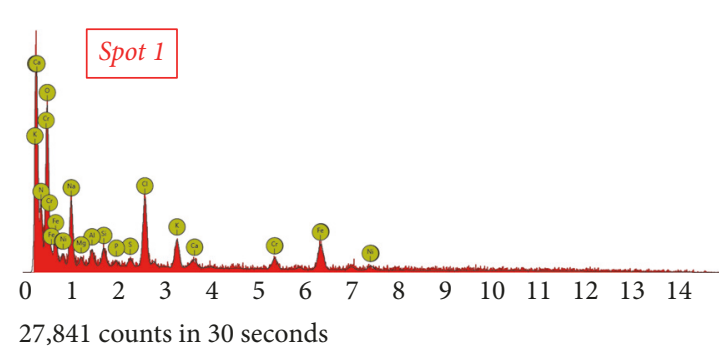

(a)

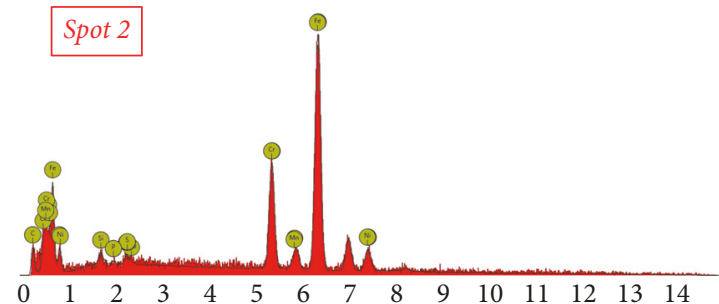

31,638 counts in 30 seconds

(b)

FIGURE 6: Spectrogram (SEM-EDS) obtained due to chemical analysis conducted in spots marked in Figure 5: (a) a corrosive sediment and (b) surface of base metal.

by increased temperature and high concentration of chlorine ions in the air. As a result of pitting corrosion attack, the tested ventilation grille corrosion products and corrosion pits were noted, as shown in Figures 2, 3, 4, and 5, especially in the heat affected zone (HAZ). The dimensions of pits on the surface of the element reached $1 \mathrm{~mm}$. The depths of pits observed on the cross-sectional surface of the test piece were approx. $0.3 \mathrm{~mm}$ (Figure 2). On the contrary, base metal was less corroded (Figure 3). On the whole, the morphology of identified pits indicates pitting corrosion attack $[6,7,10]$.

Examination of HAZ acknowledged visible severe pitting action, Figures 3 and 4(a), and generation of deep cracks 
TABLE 2: The results of chemical composition analysis at spot 1 (sediment) and spot 2 (metal surface) in Figure 5.

\begin{tabular}{|c|c|c|c|c|}
\hline \multirow{2}{*}{ Element } & \multicolumn{2}{|c|}{ Spot 1: sediment } & \multicolumn{2}{|c|}{ Spot 2: base metal } \\
\hline & Concentration [wt.\%] & Error [\%] & Concentration [wt.\%] & Error $[\%]$ \\
\hline Aluminium & 1.3 & 7.8 & - & - \\
\hline Calcium & 0.8 & 10.5 & - & - \\
\hline Carbon & 8.3 & 2.0 & 1.0 & 6.9 \\
\hline Chlorine & 5.3 & 3.0 & - & - \\
\hline Chromium & 2.1 & 7.4 & 16.8 & 2.3 \\
\hline Iron & 8.0 & 4.2 & 67.0 & 1.5 \\
\hline Magnesium & 0.9 & 13.5 & - & - \\
\hline Manganese & - & - & 1.9 & 10.5 \\
\hline Molybdenum & - & - & 1.8 & 13.1 \\
\hline Nickel & 2.0 & 12.6 & 10.3 & 5.2 \\
\hline Nitrogen & 11.0 & 3.6 & - & - \\
\hline Oxygen & 44.4 & 2.2 & - & - \\
\hline Phosphorus & 0.3 & 18.0 & 0.2 & 51.6 \\
\hline Potassium & 2.6 & 4.8 & - & - \\
\hline Silicon & 1.0 & 7.4 & 0.8 & 14.2 \\
\hline Sodium & 11.6 & 3.4 & - & - \\
\hline Sulfur & 0.5 & 12.9 & 0.2 & 16.4 \\
\hline
\end{tabular}

in between welded rods, Figures 3 and 4(b). Inside crack corrosion pits and corrosive deposits were identified. While comparing areas presented in Figure 5, it is clearly visible that the HAZ was affected by corrosion compared to the base metal. In the vicinity of the HAZ, the occurrence of pits and corrosion deposits is evident.

Results of chemical analysis of the corrosion deposits and welded steel are presented qualitatively in Figure 6(a) and quantitatively in Table 2. Spectroscopic analysis of base metal (Figure 6(b), Table 2) indicated that the investigated element could have been manufactured from stainless steel grade 1.4401 or 1.4404 (Table 1); however, it is known that the content of carbon could not be properly identified properly by SEM-EDS method. Deposits contain chemical elements which came from swimming pool environment and are used for swimming pool water treatment (e.g., Cl, Ca, Table 2). In particular, chlorine compounds play a major role in the pitting corrosion processes [6,7] and content of chlorine in deposits equals 5.3\%. In addition, the relatively high temperature of water and air in the swimming pool causes evaporation of chlorinated pool water. Ventilation systems in swimming pools often work in a closed circuit, which makes the metal elements used at the pool exposed to the effects of moist air characterized by increased concentration of chlorine ions or chlorine compounds (chloramines) [4, 7]. The mentioned factors definitely favour the occurrence of corrosion phenomena, mainly general, stress, and pitting corrosion. However, to characterize a corrosive sediment precisely, for further understanding the nature of the sediments, the XRD (X-ray diffraction) investigations should be employed. The intensification of corrosion phenomena was also influenced by poor weldment finish that accelerates deposition of corrosive elements (e.g., chlorine). In order to prevent ventilation grille from corrosion, the systematic removal of chlorine-containing sediments from its surface must be taken into account.

\section{Conclusions}

The case study on the subject of the pitting corrosion of resistance welding joints found in the stainless steel ventilation grille utilised in a swimming pool environment was investigated in the work. The following conclusions can be drawn on the basis of the conducted analysis.

The results confirmed that pitting corrosion was the main corrosion mechanism of the stainless steel ventilation grille. Heat affected zone (HAZ) of resistance welded joint of grille operated in swimming pool environment was lower than resistance of stainless steel based material.

The investigated ventilation grille was manufactured from stainless steel type $\mathrm{Cr}-\mathrm{Ni}-\mathrm{Mo}$, probably grade 1.4401 or 1.4404. Pitting corrosion affects mostly the weldment area due to its microstructure which differs from the base metal. The intensification of corrosion phenomena was also influenced by poor weldment finish which accelerates deposition of corrosive elements (e.g., chlorine).

The environment as well as the operating conditions of an element affects the corrosive wear of stainless steel grille. The increase in concentration of chlorine deposited on the corroded grille areas has been identified. Chlorine plays a major role in the pitting corrosion processes of stainless steel.

In order to prevent ventilation grille from corrosion, the removal of chlorine-containing sediments from its surface must be taken into account.

\section{Conflicts of Interest}

The authors declare that there are no conflicts of interest regarding the publication of this paper. 


\section{References}

[1] N. Baddoo and P. Cutler, "Stainless steel in indoor swimming pool buildings," Technical Note: Swimming Pools, 2007.

[2] "Stress corrosion cracking failure," http://www.corrosiondoctors.org/Forms-SCC/swimming.htm.

[3] C. Houska and J. Fritz, Successful Stainless Swimming Pool Design, Nickel Institute, 2017.

[4] "Stainless steel in swimming pool buildings - selecting and using stainless steel to cope with changes in swimming pool design," Nickel Development Institute, 2010, https://www .nickelinstitute.org/ /Media/Files/TechnicalLiterature/StainlessSteelinSwimmingPoolBuidlings_12010_.pdf.

[5] ISO 12944-1:2001, "Paints and varnishes - Corrosion protection of steel structures by protective paint systems - Part 1: General introduction".

[6] P. Sedek, J. Brózda, and J. Gazdowicz, "Pitting corrosion of the stainless steel ventilation duct in a roofed swimming pool," Engineering Failure Analysis, vol. 15, no. 4, pp. 281-286, 2008.

[7] M. Szala, K. Beer-Lech, and M. Walczak, "A study on the corrosion of stainless steel floor drains in an indoor swimming pool," Engineering Failure Analysis, vol. 77, pp. 31-38, 2017.

[8] "PN-EN 10088-1:2014 - Stainless steels. Part 1: List of stainless steels".

[9] J. Woodtli and R. Kieselbach, "Damage due to hydrogen embrittlement and stress corrosion cracking," Engineering Failure Analysis, vol. 7, no. 6, pp. 427-450, 2000.

[10] D. A. Horner, B. J. Connolly, S. Zhou, L. Crocker, and A. Turnbull, "Novel images of the evolution of stress corrosion cracks from corrosion pits," Corrosion Science, vol. 53, no. 11, pp. 34663485, 2011.

[11] C. Garcia, F. Martin, P. de Tiedra, Y. Blanco, and M. Lopez, "Pitting corrosion of welded joints of austenitic stainless steels studied by using an electrochemical minicell," Corrosion Science, vol. 50, no. 4, pp. 1184-1194, 2008.

[12] J. N. DuPont, J. C. Lippold, and S. D. Kiser, Welding Metallurgy and Weldability of Nickel-Base Alloys, John Wiley \& Sons, Inc, 2009.

[13] S. J. Kim, S. G. Hong, and M.-S. Oh, "Effect of metallurgical factors on the pitting corrosion behavior of super austenitic stainless steel weld in an acidic chloride environment," Journal of Materials Research, vol. 32, no. 7, pp. 1343-1350, 2017.

[14] I. Lenart and M. Szala, "Korozja wżerowa eksploatowanej na pływalni kratki wentylacyjnej wykonanej ze stali nierdzewnej," in PraceNaukowe Młodych Badaczy: TYGIEL, M. Szala, Ed., pp. 208-223, Lublin: Politechnika Lubelska, 2013.

[15] E. Zumelzu, J. Sepúlveda, and M. Ibarra, "Influence of microstructure on the mechanical behaviour of welded 316 L SS joints," Journal of Materials Processing Technology, vol. 94, no. 1, pp. 36-40, 1999.

[16] R. Chen, P. Jiang, X. Shao, G. Mi, and C. Wang, "Effect of magnetic field applied during laser-arc hybrid welding in improving the pitting resistance of the welded zone in austenitic stainless steel," Corrosion Science, vol. 126, pp. 385-391, 2017.

[17] J. Kim, B. Lee, W. Hwang, and S. Kang, "The Effect of Welding Residual Stress for Making Artificial Stress Corrosion Crack in the STS 304 Pipe," Advances in Materials Science and Engineering, vol. 2015, pp. 1-7, 2015.

[18] X. Li, B. Gong, C. Deng, and Y. Li, "Failure mechanism transition of hydrogen embrittlement in AISI 304 K-TIG weld metal under tensile loading," Corrosion Science, vol. 130, pp. 241-251, 2018.
[19] H. Leda, "Materialy inzynierskie w zastosowaniach biomedycznych," Wydawnictwo Politechniki Poznanskiej, 2012.

[20] E. A. Abd El Meguid, N. A. Mahmoud, and S. S. Abd El Rehim, "Effect of some sulphur compounds on the pitting corrosion of type 304 stainless steel," Materials Chemistry and Physics, vol. 63, no. 1, pp. 67-74, 2000. 


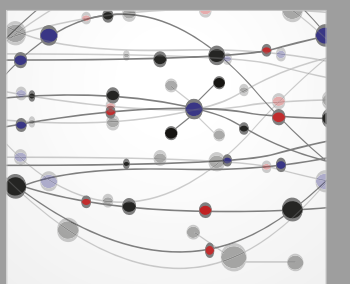

The Scientific World Journal
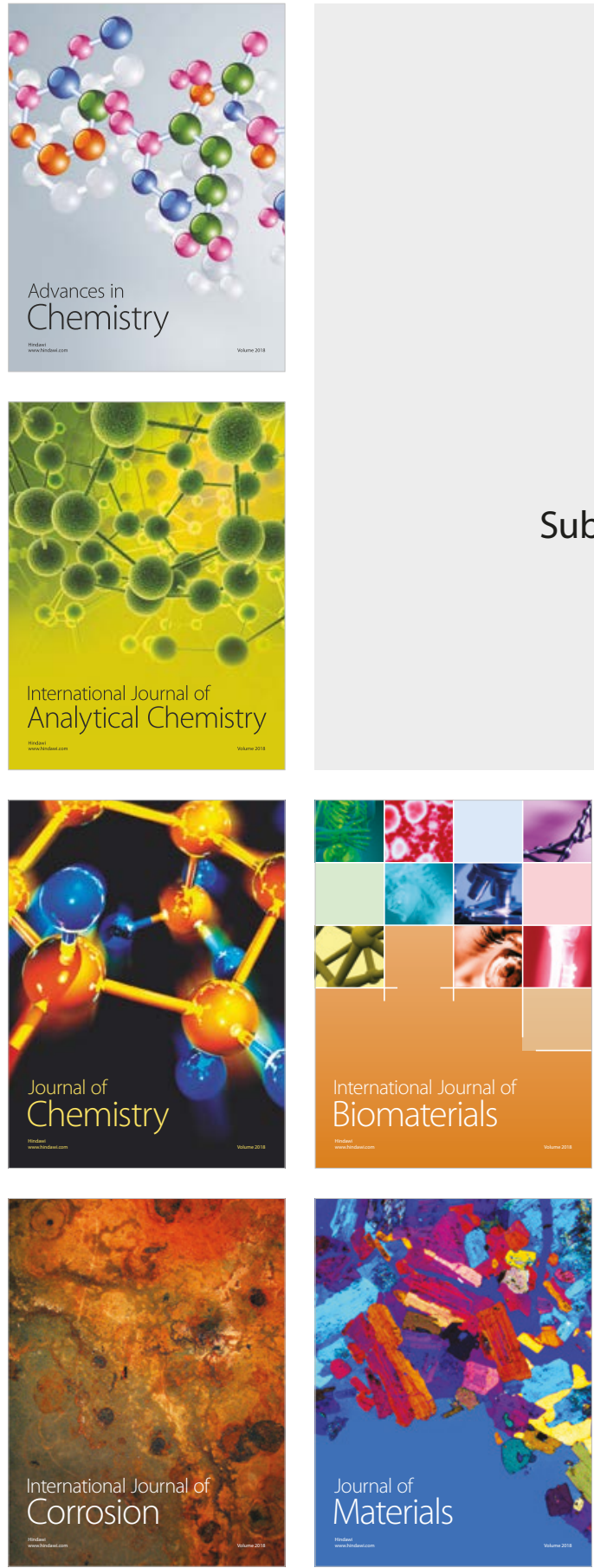

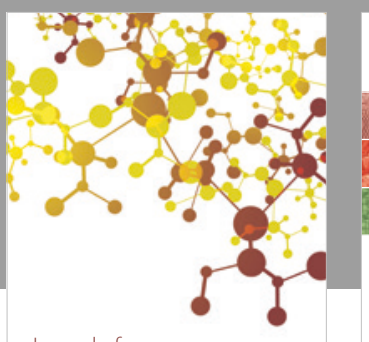

Journal of

Applied Chemistry
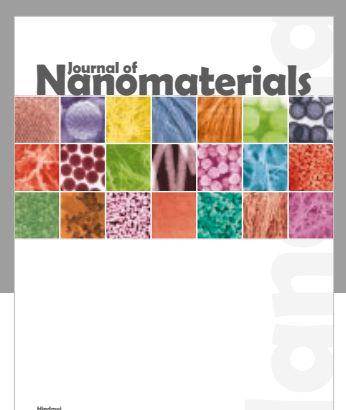

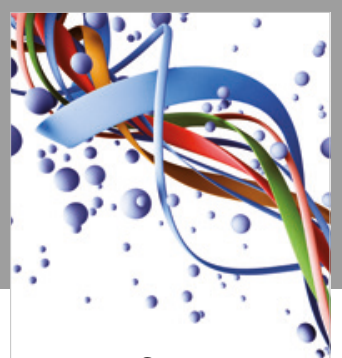

Scientifica

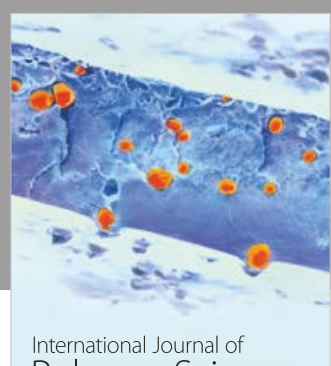

Polymer Science

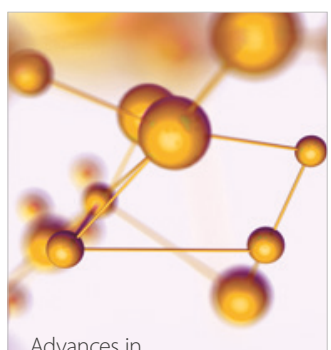

Physical Chemistry
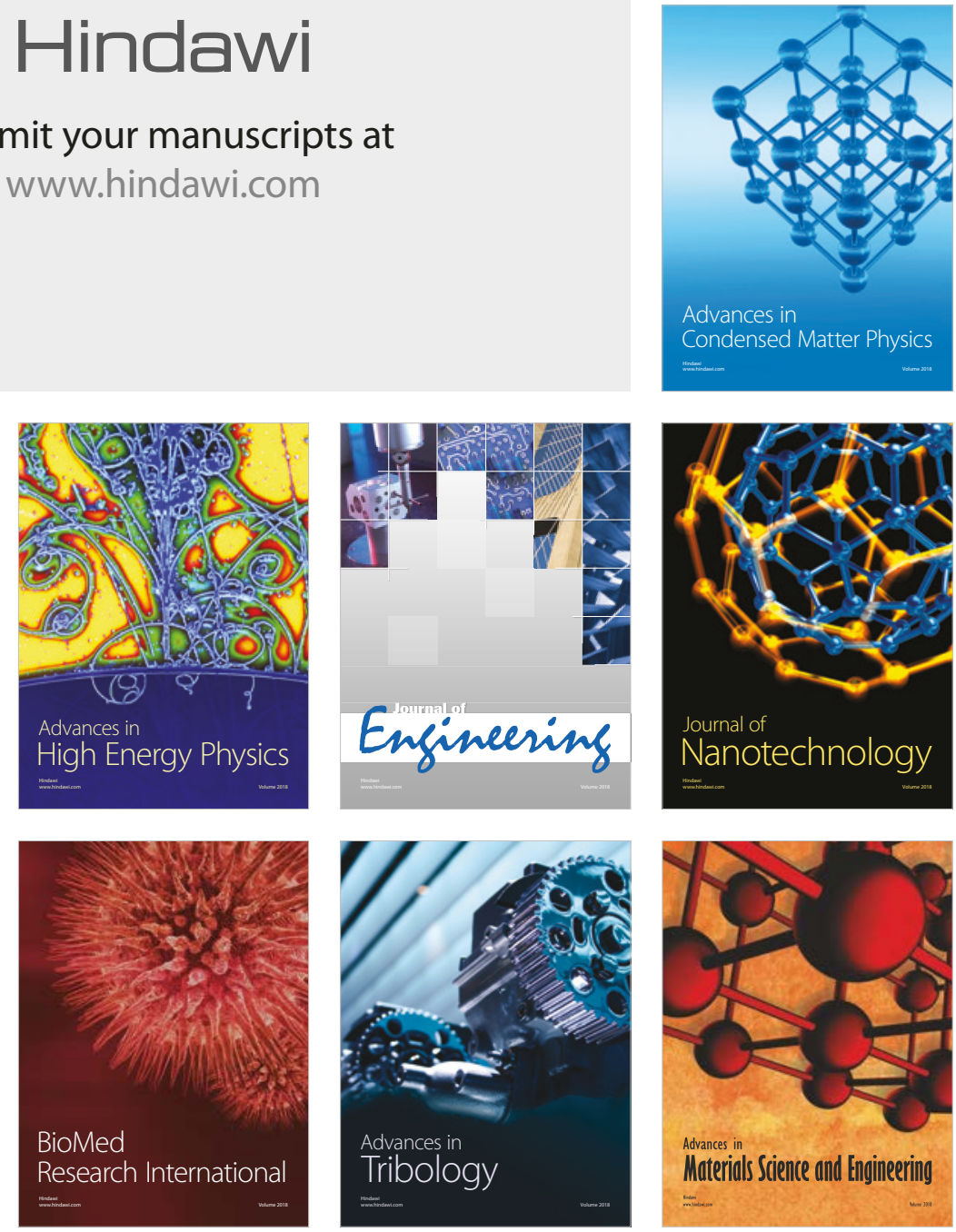